\title{
Plant Breeding in Sub-Saharan Africa in an Era of Donor Dependence
}

\author{
John Lynam*
}

\begin{abstract}
Since the Asian Green Revolution, plant breeding has been seen as a core capacity in most agricultural research institutes around the world, including those in Africa. Outside some private sector breeding for hybrid maize in East and Southern Africa, plant breeding is essentially a public sector activity and over the last four decades has relied significantly on international development assistance, and so has been susceptible to shifts in donor funding for agricultural research. The performance of programmes has been affected by these trends, with the balance between the scale economies in plant breeding and the local adaptation needed to satisfy farmer demand influenced by a complex and sometimes problematic division of labour between the international agricultural research centres (IARCs) of the Consultative Group on International Agricultural Research (CGIAR) and the breeding programmes of National Agricultural Research Institutes (NARIs).
\end{abstract}

\section{The unique nature of the plant-breeding problem in sub-Saharan Africa}

In no other region of the world is plant breeding more difficult, less resourced and more needed than in sub-Saharan Africa. Some indication of the difficulty inherent in successful plant breeding in Africa is that by 2000, only about 22 per cent of the food crop area was planted to improved varieties; half of these developed by CGIAR centres and the other half from NARI programmes and others (Maredia and Raitzer 2006). This is well below other regions in the developing world (Table 1). Achieving widespread impact with a few new varieties has a very low probability of success in sub-Saharan Africa, as the context is so very different from that of Asia or Latin America. Agriculture in Africa is almost completely reliant on rain-fed cropping systems, as only about 4 per cent of arable land is irrigated, and more often than not, in environments that have relatively high variability in rainfall and where plant nutrients are limiting.

This temporal variability, together with a plethora of biotic and abiotic constraints is nested within a high degree of spatial variability. This complexity results in higher costs for plant breeding in Africa compared with other regions, given the need to breed for more restricted environments, and increases the number of breeding objectives that must be incorporated into the breeding programme.

This context is complicated further by the structure of African farming systems. Apart from some areas of Southern Africa, agricultural production on the continent is dominated by small-scale farming. Because there are high transaction costs in market participation, there is a significant subsistence component with marked quality preferences for principal staples. Input markets are equally underdeveloped and fertiliser usage averages less that $10 \mathrm{~kg}$ per hectare. Moreover, because of the significant market and production risks associated with smallholder farming, there is a striking diversity in production patterns. There is not only a mix of food staples, but farmers will also usually maintain a portfolio of varieties that individually do not meet all the production and consumption objectives, but together ensure subsistence requirements under risk (Minot et al. 2007). This diversification reduces the potential returns to the use of improved practices for particular commodities and more generally inhibits farmer interest in increasing agricultural productivity (Sumberg and Blackie 2004). 
Table 1 Productivity growth by region and contribution of plant breeding

$$
\begin{aligned}
& \text { Share of area planted to } \\
& \text { modern varieties (\%) }
\end{aligned}
$$$$
\text { Contribution }
$$

Contribution
of crop genetic $\quad(\mathrm{kg} / \mathrm{ha})$
improvement
to yield growth

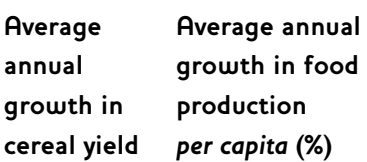

(\%)

\begin{tabular}{lcccccccc}
\hline & $\mathbf{1 9 7 0}$ & $\mathbf{1 9 8 0}$ & $\mathbf{1 9 9 0}$ & $\mathbf{1 9 9 8}$ & $\mathbf{1 9 6 0 - 9 8}$ & $\mathbf{2 0 0 0}$ & $\mathbf{1 9 8 0 - 2 0 0 0}$ & $\mathbf{1 9 8 0 - 2 0 0 0}$ \\
\hline Asia & 13 & 43 & 63 & 82 & 0.88 & 3.662 & $\mathbf{2 . 3}$ & $\mathbf{2}$ \\
Latin America & 8 & 23 & 39 & 52 & 0.66 & 2.09 & 1.9 & 0.90 \\
Middle East and North & 4 & 13 & 29 & 58 & 0.69 & 2.660 & 1.2 & 1.00 \\
$\begin{array}{l}\text { Africa } \\
\text { sub-Saharan Africa }\end{array}$ & 1 & 4 & 13 & 27 & 0.28 & 1.112 & 0.7 & -0.01 \\
\hline
\end{tabular}

Source Adapted from the Forum for Agricultural Research in Africa (FARA 2006).

The history of variety development in subSaharan Africa by the GGIAR centres started in the 1970 s with testing through international varietal trials and the search for broadly adapted varieties. This approach, while successful for wheat under Asian conditions, was found to be highly inefficient for maize under African conditions, where the crop was grown in a range of agro-ecologies under limited input use (Kling 2007). The 1980s was a period in which many of the IARGs developed breeding capacity in Africa that produced adapted germplasm. No centre has had success in breeding without developing African populations and moving them into selection in regional networks. The issue of how many environments to breed for in Africa still remains to be fully tested by most centres, however, as does the issue of how many breeding objectives and selection criteria are necessary to effectively compete with local varieties that have been selected over centuries for adaptation to local conditions.

A central question is how differentiated do cropbreeding programmes have to be in order to be successful and at what cost? As an example, Kenya organises its maize breeding around six distinctive agro-ecologies, but is their capacity for such an approach sufficient and what is the potential for importing materials for some of the less important ecologies? The complexity of the breeding problem in Africa has thus led to a combination of national and regional approaches in the development of adapted varieties, in particular developing specific traits in populations through pre-breeding and then feeding these into national breeding programmes.

The complexity of breeding in Africa is further compounded by the inherent difficulty of developing commercial seed systems for dominant food staples. A significant diversity of such food staples are grown in Africa and hybrid technology - the primary basis for development of commercial seed companies - has been limited to maize, mainly for use in East and Southern Africa, particularly Kenya and Zimbabwe. Hybrid sorghum and pigeon pea are also possible, but have not been applied in Africa because of the lack of a well-developed seed system. Other food staples in Africa are either clonally propagated (root crops and Musa) or are open-pollinated varieties (OPVs). In areas where commercial horticulture has developed, such as the irrigated areas of the Sahel and the highland areas of East and Central Africa, hybrid seed is also used, but it is generally imported.

Developing improved varieties for the food economies of Africa is further complicated by the lack of incentives in the development of private seed markets and a dependence on publicly funded approaches in delivering seed of improved varieties to farmers.

\section{The changing aid architecture}

Agricultural research capacity has been built in sub-Saharan Africa through heavy reliance on donor funding. Foreign aid in support of agriculture overall peaked in the mid-1980s (when measured as a percentage of overall aid 
flows) and has steadily declined since then. Only with the recent spike in food prices has aid to agriculture started to increase again. In general, this pattern is also reflected in donor support to national agricultural research (Pardey et al. 2007). As Eicher (2001) notes, the 1980s was the golden age for support to agricultural research in Africa. Specifically designed grants and loans for agricultural research focused on institutional building, particularly in the form of semiautonomous national agricultural research institutes. For many countries, such as Malawi, this was the period when a maize-breeding team was trained and the breeding programme structured, which would lead to the release of the first semi-flint maize hybrids in 1990 (Smale and Heisey 1994).

The downturn in funding to agricultural research in Africa in the 1990s reflected a significant shift in overall funding priorities, as well as the approach to funding agricultural research. With declining agricultural budgets, the focus shifted to regional approaches, both in terms of support to regional research networks operated by CGIAR centres, and to the creation of sub-regional agricultural research organisations. Thus, the Association for Strengthening Agricultural Research in Eastern and Central Africa (ASARECA) was established in 1994 and followed by the Conférence de responsables de recherche agronomique africains (CORAF or the West and Gentral African Council for Agricultural Research and Development, WECARD), both modelled on the longer-established Southern African Centre for Cooperation in Agricultural and Natural Resources Research and Training (SACCAR). Moreover, this was the period of structural adjustment and market liberalisation, and donors were concerned about the lack of rapid uptake of new technologies from the investment in agricultural research, despite studies which provided evidence of significant impact to these investments (e.g. Oemke 1992). This was also a period of serious political unrest in several countries in the region. Accordingly, several donors shifted priorities to give greater attention to governance policies and economic enterprises. Agricultural research was regarded as an investment which would be less likely to produce the 'quick wins'.

Despite the shift in donor priorities, national agricultural research systems continued to rely on donor funding for a significant part of their expenditures, although this varied significantly across countries. Thus Pardey et al. (2007) observe, 'Donor contributions (including World Bank loans) accounted for an average of 35 per cent of funding to principal agricultural research agencies in 2000'. Only five years earlier, close to half the agricultural research funding in the region was derived from donor contributions. Through the middle of this last decade, donor support to national systems has continued to fall and the World Bank was left as virtually the only donor to national systems, apart from the technical assistance offered by L'Institut de recherche pour le développement (IRD or the Development Research Institute), mainly in francophone countries. ${ }^{1}$

For some countries, such as Malawi, donor funding for agricultural research has virtually stopped, with the focus now on improving productivity under the input subsidy programme (see Chinsinga, this IDS Bulletin; World Bank 2008).

Selective donor support for agricultural research in Africa is leading to a stratification of research capacity across countries, with a small cohort of relatively strong systems like the Kenya Agricultural Research Institute (KARI) and the Crops Research Institute (CRI) in Ghana. The implication is that this lack of capacity at national level will be replaced either by regional programmes, by the private sector, by spill-ins from international companies (such as in Central America) or by the CGIAR.

Agricultural research capacity has not only been influenced by funding trends but also by significant shifts in approaches to how agricultural research is organised and managed. Projects in the golden age in the 1980s focused on consolidating agricultural research units spread across different ministries and departments into a semi-autonomous parastatal or a national agricultural research institute. Thus, World Bank lending during 1980-95 focused mostly on capacity building. Over 60 per cent of the Bank's commitment to research during the period went to free-standing projects, aimed mostly at strengthening and expanding the capacities of particular agencies and human resource development projects strongly supported postgraduate training and recruitment (Purcell and Anderson 1997). This 
emphasis shifted in the 1990 s to developing more decentralised, pluralistic systems and delinking funding and research execution, primarily through the creation of umbrella research councils. For small African countries with embryonic private sectors and limited research capacity in universities, this resulted in the decentralisation of the research stations in the NARIs to semi-autonomous institutes, thus undercutting any potential economies of scale in areas like plant breeding and creating problems of coordination in areas like varietal testing.

The most recent change to funding of agricultural research in Africa was the creation in 2006 of the Global Development Program within the Bill and Melinda Gates Foundation (BMGF), with a principal focus on agriculture and with a significant component supporting agricultural research. In turn, the BMGF, together with the Rockefeller Foundation were instrumental in creating the Alliance for a Green Revolution in Africa (AGRA), which is providing support in the areas of plant breeding $(\$ 100$ million) and soil health (\$164 million). Large grants given by BMGF tend to be multi-country in scope but with a relatively narrow subject or thematic focus. Many of the projects in the area of science and technology have a crop improvement focus, whether by conventional breeding or transgenic approaches. AGRA, on the other hand, has a programme dedicated to crop breeding and seed system development the Programme for Africa's Seed Systems (PASS). This programme primarily funds individual breeding programmes or start-up activities in seed companies.

Today, there is a complicated mosaic of donor support for agricultural research in sub-Saharan Africa, on which NARIs still depend to varying degrees. The World Bank, the largest traditional funding agency for national research systems, has moved away from standalone projects for agricultural research and focuses mainly on providing indirect support through other agricultural loans. In some cases, such as the Kenya Agricultural Productivity Programme (KAPP), there is explicit funding for KARI, but bundled together with support for extension and farmers' associations and in the second phase with strategic partnerships with the private sector. This has created significant disparity in capacity across national systems, when other donors such as the European Union (EU) and USAID are focusing much more on supporting regional approaches through the sub-regional organisations (SROs) and the regional economic communities (RECs). ${ }^{2}$ Finally, the new funding from the foundations is directed to very strategic areas where there is already some capacity on which to build. Capacity in plant breeding could be developed at both national and regional level and be linked to global programmes in the CGIAR, but these connections have yet to be properly established. Closer coordination is needed, both between those implementing these breeding programmes and those funding them, if this emerging plant-breeding potential is to be realised, a theme which will run through much of the rest of this article.

\section{Plant-breeding capacity and institutional arrangements}

To be effective, formal plant breeding requires an integrated organisation combining different functions and a combination of centralised and decentralised activities, particularly in subSaharan Africa. The plant-breeding activities of the multinational bioscience companies are organised globally under one management and financing structure and are fully integrated with seed production and market development. In contrast, in sub-Saharan Africa different functions are carried out by different public sector organisations and financing decisions are made by other, primarily donor, organisations at different levels of the hierarchy, often for higherorder objectives not directly related to the needs of plant-breeding capacity and organisation. Different funding priorities at different levels of the plant-breeding system have resulted in both asynchronous development of different parts of the formal plant-breeding system, as well as creating significant problems in coordinating a multi-scale plant-breeding system. The financing component was briefly surveyed above. In this section, the institutional arrangements between the three principal actors in plant breeding namely the SROs, NARIs and IARGs - are surveyed.

The experience of supporting a myriad of small agricultural research institutes in the 1980s gave way in the 1990s to donor support for sub-regional approaches through the three sub-regional organisations. By the beginning of this decade, ASARECA had become a coordinating platform 
for 17 networks. This platform was viewed as a mechanism for achieving ASARECA's overall objectives to: '(1) make spillovers happen across national boundaries; (2) achieve economies of scale and scope in research; (3) produce regional public goods; (4) provide a mechanism to share benefits and costs of collective action; and (5) find research solutions to transboundary problems' (Oruko 2008). Seven of these networks were cropfocused and supported a regional breeding programme. In turn, synergies were sought with networks on plant genetic resources, policy analysis, biotechnology and biosafety, soil and water management, post-harvest issues and agricultural information. These interacting networks provided a range of support in terms of training, operational funds and access to CGIAR research during a period in which NARIs were going through 'an era of stagnation' (Beintema and Stads 2006).

In 2007, ASARECA restructured its governance by expanding representation beyond just NARI directors and completely recast its strategy, devolving the networks and developing a programme structure around seven core themes, which would primarily run competitive grant programmes. USAID, the EU and the UK Department for International Development (DFID) supported this restructuring process and in turn shifted all of their funding from the networks to the competitive grant programmes, in the process severing close partnership arrangements between ASARECA and the CGIAR centres. As will be seen, this effectively curtailed a significant number of regional breeding programmes. The same process took place in CORAF in West Africa. Competitive grants are not well suited to the needs of an ongoing breeding programme, however, as they require sustained investment. At the same time, the new approach cut links between IARC and NARI breeding programmes in a large number of cases, further reducing opportunities to strengthen research capacities at country level.

The organisation of plant-breeding programmes in the CGIAR in general consists of a three-stage process: (1) a centralised breeding platform linked closely to a world germplasm collection; (2) a set of regional breeding programmes drawing on support from the central unit; and (3) differentiated support by regional networks to national breeding programmes depending on their capacity. During the 1990s many of the regional breeding programmes were on an equal footing with the breeding programme at headquarters, but the addition over the last ten years of molecular characterisation of the germplasm bank, molecular breeding using markers, integrated information systems linking genetic, genotype and phenotype information and transgenic platforms have all led to a significant increase in services provided by the centralised breeding platforms to the regional networks. These programmes also generally support international varietal testing networks, which are often integrated with testing networks in the different regions. There is a lot of variation across the CGIAR system, however, in how such breeding programmes are organised, either by commodity or by region. National breeding programmes, in turn, can access different germplasm products from international research centres depending on the capacity of their breeding programme. If the whole system functions properly, farmers across the developing world should have access to an increasing array of locally adapted varieties that lead to increasing farm-level benefits over time. Unfortunately, the system is far from optimal.

The regional breeding programmes of the CGIAR for five commodities are presented in Table 2. Several broad trends are apparent in the table. First, regional breeding programmes have been much more common in sub-Saharan Africa, reflecting in part the number of small countries and the more limited capacity in national programmes. Second, as might be expected, the IARCs usually do not have networks in the region in which the headquarters are based (the International Institute of Tropical Agriculture [IITA] and the Africa Rice Centre[WARDA] would be exceptions). Finally, many regional breeding programmes have had to close over the last decade or so due to the inability to source adequate funding. In Africa, most of the closures were due to the shift in funding by USAID and the EU from support from commodity networks to competitive grant programmes within the SROs.

Regional breeding networks all have some form of centralised breeding capacity run by the international centres. In general, it has taken some time to develop breeding populations adapted to the constraints prevailing in the region and the quality characteristics demanded in the 
Table 2 Regional crop breeding networks operated by CGIAR centres

\begin{tabular}{|c|c|c|c|c|}
\hline Commodity & IARC & LAC & Asia & Africa \\
\hline Maize & CIMMYT & None & Terminated & ECAMAW \\
\hline Maize & IITA & None & None & $\begin{array}{l}\text { Terminated } \\
\text { West Africa }\end{array}$ \\
\hline Cassava & CIAT & None & Terminated & None \\
\hline Cassava & IITA & None & None & $\begin{array}{l}\text { Terminated } \\
\text { East, West } \\
\text { S. Africa }\end{array}$ \\
\hline Beans & CIAT & None & None & $\begin{array}{l}\text { ECABREN } \\
\text { SABREN }\end{array}$ \\
\hline Rice & $|R R|$ & None & None & ECARRN \\
\hline Rice & CIAT & FLAR & None & None \\
\hline Rice & WARDA & None & None & $\begin{array}{l}\text { ECARRN } \\
\text { ROCARIZ }\end{array}$ \\
\hline Vegetables & AVRDC & None & None & vBBS Hubs \\
\hline
\end{tabular}

AVRDC, World Vegetable Centre; CIAT, International Centre for Tropical Agriculture; CIMMYT, International Maize and Wheat Improvement Centre; ECABREN, East and Central Africa Bean Research Network; ECAMAW, Eastern and Central African Maize and Wheat Research Network; ECARRN, Eastern and Central African Rice Research Network; FLAR, Latin American Fund for Irrigated Rice; IRRI, International Rice Research Institute; ROCARIZ, West Africa Rice Research Network; SABREN, Southern Africa Bean Research Network; vBBS Hubs, Vegetable Breeding and Seed Systems; WARDA, Africa Rice Centre.

market. This was true for CIAT's bean-breeding programme in East Africa, WARDA's rice programme in coastal West Africa and CIMMYT's maize breeding in East and Southern Africa. Virtually all CGIAR centres with crop-breeding mandates have had to develop regional breeding programmes in sub-Saharan Africa given the range of constraints on crop productivity in essentially rain-fed systems, as well as the limited input use by smallholder farmers. There has been almost no adoption of varieties bred outside of Africa except for vegetables and potatoes, and these are grown under higher input use and better crop management.

There is a basic assumption in the organisation of these networks that pre-breeding and other services that support a distributed set of national and sub-national crossing and selection programmes will produce a flow of adapted varieties superior to what could be achieved from a large, centralised breeding programme with regional or international testing, on the one hand, or an uncoordinated, decentralised set of national breeding programmes on the other. The greater efficiency of large centralised breeding programmes has been argued for in the case of wheat breeding (Maredia and Byerlee 2000; Byerlee and Traxler 2001). Such a centralised system also characterises the organisation of maize breeding by private corporations like Monsanto and Pioneer in Africa, where each maintains one crossing and selection site on the continent, as opposed to the 3-4 sites they maintain in Asia. Size of crossing blocks and the attendant genetic variability, widespread testing and data integration and movement of germplasm between selection sites is projected to lead to the development of regional markets for varieties, a strategy that has been less successful so far in Africa than it has in either Asia or Latin America.

On the other hand, there are strong arguments in favour of regional breeding programmes for sub-Saharan Africa (Kling 2007; DeVries and Toenniessen 2001). As Kling (2007) notes:

'Broad' adaptation is used in some instances to refer to adaptation across wide geographic areas within a defined agroecology, and in 
other instances to refer to adaptation across multiple agroecologies. In the latter sense, where $\mathrm{G} \times \mathrm{E}$ exists [i.e. where the effects of genotype $\times$ environment interaction $(\mathrm{G} \times \mathrm{E})$ on genetic gain in breeding programmes], selection for broad adaptation is similar to selection for multiple traits. Simultaneous selection for multiple environments may decrease the rate of progress that could be achieved through selection for specific adaptation to a single environment.

Most regional breeding programmes, as well as many national programmes, will stratify their breeding programme by agro-ecologies and work within acceptable levels of $\mathrm{G} \times \mathrm{E}$ interaction. Such stratification then produces the potential for a clear division of labour between breeding programmes within the network.

In sub-Saharan Africa, international and regional breeding capacity is not a substitute but rather a very strong complement to plant-breeding capacity at the national level. This runs counter to the assumption that underlies the significant literature on technological spill-ins, in which scale economies in breeding allow more cost-effective varietal development in either larger countries or within either the public or private international system. Certainly, this assumption underlies the increasing investments by multinational seed companies in strategic regional plant-breeding capacity that will serve a range of markets in smaller and medium-sized countries. However, the literature on this subject is based essentially on the case of wheat (Byerlee and Dubin 2008; Maredia and Byerlee 2000; Byerlee and Traxler 2001) and the argument here is that wheat is something of a special case given the temperature limits on where it is grown (i.e. outside the lowland tropics), the predominate production systems (i.e. irrigated), and the principal constraints (i.e. disease) (Traxler and Pingali 1999).

Bean breeding at CIAT, cassava breeding at CIAT and IITA and maize breeding at CIMMYT and IITA followed very much the trend of rice breeding at IRRI, but for somewhat different reasons. In the 1970 s and 1980s, they were characterised by large centralised breeding programmes with a principal focus on cultivar development feeding into an international varietal testing network. However, these programmes had to breed for crops grown primarily under rain-fed conditions and across a wide range of production ecologies. As noted above for maize in CIMMYT, breeding progress to meet the needs of farmers across these diverse agroecologies was limited and it was difficult to demonstrate adoption and impact. This was especially true in sub-Saharan Africa, where trends in per capita food production were declining. This situation led to a regionalisation of the CGIAR's breeding programmes during the latter part of the 1980 s and into the 1990s, with a special focus on sub-Saharan Africa. This regionalisation occurred just as the potential of molecular approaches in plant breeding were being developed in advanced labs and were being linked to capacity in the developing world, particularly through the Rockefeller Foundation's Rice Biotechnology Program. These two trends started to create more of a distinct division of labour between headquarters and the regional programmes, with headquarters focusing increasingly on trait development, molecular markers, transgenic approaches and highly focused pre-breeding.

While the division of labour between the headquarters breeding platform and the regional breeding programme was becoming better defined, that between the regional breeding programme and the NARI was characterised by some diversity in approach. The experience of the regional networks suggests four alternative organisational models for IARG-NARI plantbreeding interaction at a regional level. These alternatives depend on: (1) breeding methods employed in the crop itself; (2) agro-ecological and market variation; (3) the capacity of the national programmes; and (4) the investment resources available. These organisational models are described as follows:

1 Centralised cultivar development. The GGIAR regional plant-breeding programme develops fixed lines which are either tested in a regional varietal trial or integrated into the national performance trials of individual countries. For countries with a crossing programme, varieties may enter as a parent, but that is relatively inefficient compared to the provision of nurseries and populations.

2 Centralised crossing and dispersed selection. This model is particularly used in rice and is especially useful when priority traits are common to a region but their combination will vary across markets or production 
systems. Thus, WARDA can feed into its crossing block traits from wide crosses and work with a significant range of genetic variability, but then the early generations undergo selection across a wide range of conditions in national programmes.

3 A division of labour across multiple breeding projects. This derives primarily from the CIAT beanbreeding model. Consumer traits such as colour and grain size, where preferences vary by country, must be segregated into different breeding populations and these must in turn be combined with disease and pest resistances specific to principal agro-ecologies. Each national programme can thus concentrate on the market type most demanded in their country but draw on varieties from other programmes for more minor market types or agro-ecologies.

4 Centralised population breeding supporting national crossing and selection programmes. This model appears to be particularly applicable to subSaharan Africa, at least in terms of the combinations of traits that need to be assembled for particular agro-ecologies at a regional level. Such pre-breeding within broad agro-ecologies could feed directly into national crossing and selection programmes or into the other three models, depending on capacity at the national level.

Were resources to be unconstrained, the optimum configuration for sub-Saharan Africa would be the fourth model, given that most countries are small to medium-sized, rain-fed agriculture predominates, there is a broad range of agro-ecologies but significant heterogeneity within even smaller countries and the scope for intensification of crop management practices is still limited. However, the potential to develop further effective models of IARG-NARI institutional arrangements in plant breeding have been curtailed by the loss of donor support. On the whole, regional breeding networks have deteriorated significantly in the last decade, and yet remain a critical mechanism for effective plant breeding on the continent.

\section{Building a functional plant-breeding capacity in Africa}

The post-independence history of plant-breeding capacity and impact in sub-Saharan Africa has been intimately coupled to the significant shifts in funding for agricultural research and with its very rapid changes in 'paradigms' relating to the most effective organisational modalities for research systems on the continent (Sumberg 2005). At the same time, plant breeding has its own particular organisational architecture which relies heavily on predictable recurring financial support, continuity and long investment horizons. Sometimes these shifting paradigms have been congruent with the needs of a functional plantbreeding system, but more often have been destabilising. Furthermore, plant-breeding architecture is inherently hierarchical and in an African context must balance centralised and decentralised functions. Given these challenging contexts, this concluding section will summarise the characteristics of an ideal plant-breeding system for sub-Saharan Africa.

The plant-breeding challenge in sub-Saharan Africa is to optimise existing genetic diversity in order to match the agro-ecological, cropping system and consumption system heterogeneity that characterise agricultural production on the continent. Farmers and communities employ a wide range of plant genetic diversity within their production systems and the challenge for plant breeding is to improve productivity and yield stability of cropping systems, while exploiting that genetic diversity. This objective must be reached within the context of ensuring costeffectiveness of breeding programmes, exploiting the economies of scale in plant breeding (and the potential of molecular methods to improve the effectiveness of deployment of priority traits), and ensuring local adaptation that motivate farmer adoption. Because of the 'small country' problem in organising agricultural research in national systems together with the constraints on NARI capacity, cost-effective plant breeding requires the integration of germplasm and information flows between national crossing, selection and testing systems with IARC regional breeding programmes with particular capacity to develop adapted populations incorporating priority traits, and links to global capacity in trait development, molecular methods and potentially transgenic approaches for intractable constraints. These three functional levels generally are financed by quite different funding sources, which allows for focusing on innovation and needs at each level but which often limits effective integration within the overall system. 


\subsection{Global breeding platforms and molecular breeding methods}

Molecular breeding approaches, from markerassisted selection (MAS) to integration of transgenics in elite line development, may be useful in breeding programmes. There was something of an early rush to argue that these techniques have particular applicability in the sub-Saharan African context, where there is urgent need for improved crop productivity. There have been a range of programme initiatives supported primarily by bilateral donors that focused largely on building human capacity linked to specific research applications, often within a university context and where molecular labs were developed. The development of molecular labs within NARIs has been more sporadic and usually linked to particular research programmes. There are few if any instances of investments by national governments in agricultural biotechnology outside of South Africa, nor are there any instances of MAS being used in national crop breeding programmes. It remains a question as to whether greater efficiency gains can be had by focusing on conventional breeding programmes.

Molecular breeding approaches facilitate more efficient manipulation of traits within breeding programmes and involve a range of different applications. They are an effective mechanism for ensuring incorporation of target traits into populations for different agro-ecologies. MAS can also be used for pyramiding genes into elite cultivars, so called 'meta-varieties', where commercial varieties have an increasing number of other desired traits. In Africa, this approach is occasionally turned on its head in incorporating resistance traits into principal landraces already widely grown by farmers, and has been particularly applied in grain legumes. For example, CIAT has used markers in their prebreeding of beans, for the incorporation of traits from wild relatives into breeding populations for commercial grain types (Acosta-Gallegos et al. 2007). Most of the GGIAR centres now employ MAS in at least part of their pre-breeding work for sub-Saharan Africa. Finally, in more centralised crossing blocks, such as are used by WARDA, markers can reduce early progeny size and thereby increase the number of environments for early selection and evaluation, a particularly critical application in an African context.
Most of these applications argue for the use of MAS in more centralised breeding programmes, either in the pre-breeding stage or the early generational stage, ensuring deployment of target traits within the frame of decentralised selection and evaluation from sufficient genetic variability. Moreover, marker-assisted backcrossing is quite effective for introgressing simple inherited traits (e.g. disease resistance) to provide incremental improvement of already adapted cultivars. The costs of MAS are a function of the number of materials to be screened and the automation and throughput of the laboratory. There is no highthroughput marker lab in sub-Saharan Africa and turnaround time is critical to effective selection, potentially limiting the use of large private labs in the North and in China. The operational costs that support the application of MAS are principally project driven and organised around key traits, as for example with drought resistance, and primarily done through a few IARCs with well-developed molecular labs, such as CIMMYT and CIAT. In the future, stability of funding may have a significant impact on capacity for applying molecular breeding methods.

\subsection{Regional breeding networks}

Regional breeding networks are central to development of a plant-breeding system on the continent. An opportunity exists to do this through the commodity-based CGIAR Research Programmes being developed as part of the CGIAR reform process. For example, the relatively new programme of the International Potato Centre (CIP) on sweet potato breeding in sub-Saharan Africa was funded by the Gates Foundation and is designed around three regional agro-ecological breeding programmes that feed materials to national breeding programmes whose capacity is being strengthened partly by AGRA funding. These new initiatives provide an opportunity to draw on past experience in the design of these breeding programmes, with a particular focus on thinking through the mode of interaction between the centralised breeding programme and the national breeding programmes.

Plant breeding is an information-intensive activity that can benefit greatly from applying modern information systems to integrate spatial analysis through geographic information systems (GIS) with phenotypic data from multi-location trials, and increasingly with genotypic data from molecular characterisation. Spatial databases for 
Africa are now increasingly available and can be used to select optimally the number and location of trial sites in relation to agro-ecological variance. Modern breeding relies heavily on gathering, understanding and applying multiple sources of information about the genetic makeup of the plants connected to their performance in multiple environments. An efficient trialling network is a first essential component of any national or regional breeding programme, allowing effective testing of introduced varieties from other breeding programmes, characterisation of potential parents, and evaluation of advanced breeding lines. But trialling sites are generally chosen on a relatively ad hoc basis, with only limited understanding of the extent to which they represent the 'population' of target environments for production. Given the spatial heterogeneity problem that challenges plant breeding in Africa, greater investment in testing and trial capabilities is needed both within countries and on a regional basis and the regional breeding networks could play a central role in coordinating the development of this capacity.

\subsection{NARI breeding capacity}

Unfortunately, the funding process in many national agricultural research institutes and systems is not conducive to consistent, sustainable support for breeding programmes, given that allocation decisions are made at higher management levels and respond to a plethora of short-term needs. Functional plantbreeding capacity, where it exists in sub-Saharan Africa, has depended on recurring outside sources of funding. Today, building national plant-breeding capacity within the context of increased investment in national agricultural research institutes is possible only in a few countries, such as Kenya and Ghana.

If functional plant-breeding capacity is to be recognised as a critical component in increasing agricultural productivity, more direct means of providing working capital to the programmes are needed. Several alternatives are emerging. The programme that comes nearest to meeting this objective is AGRA's Programme for Africa's Seeds Systems (PASS), and particularly the programme element called Fund for the Improvement and Adoption of African Crops (FIAAC). FIAAC provides funds primarily for crop-breeding programmes in national research institutes. The mechanism provides 3-5 year grants, potentially renewable, with the objective in ten years to have released over 1,000 new crop varieties. However, the funding tends to focus narrowly on individual breeders rather than the national crop-breeding programme itself. This does not necessarily ensure effective linkages to breeding programmes of the CGIAR centres, but rather encourages breeding networks within their own programme structure.

It is too early in the CGIAR reform process to know whether development of sustained core funding for centre programmes will allow improved coordination and further consolidation of a comprehensive plant-breeding system for sub-Saharan Africa.

The recent trend, however, has been for IARC's breeding programmes to emphasise a more global posture with increased work on new breeding methods and biotechnology. There is, as a result, an increasing separation in the evolution of the CGIAR, on the one hand, and the sub-Saharan African platforms on agricultural research, on the other - namely the Comprehensive Africa Agriculture Development Programme (CAADP) of the African Union's New Partnership for Africa's Development (NEPAD), the Forum for Agricultural Research in Africa (FARA) and its Framework for African Agricultural Productivity (FAAP) and the three SROs. This is a process that could be reversed with the development of regional platforms organised around plant breeding.

\section{Conclusions}

Plant-breeding capacity in sub-Saharan Africa is something of a bell-wether for the expansion and contraction of agricultural research, for various fads of donor support for agriculture, for market liberalisation and expanding input markets and for the application of advanced science and technology in the region. It is easy to argue that national governments should invest more in plant breeding but because plant breeding is a long-term investment requiring recurring commitment, it does not have as much policy visibility or impact compared to interventions like a targeted fertiliser subsidy programme. Nor given current budgeting and financial resource allocation systems will it be easy to increase spending in plant breeding. These underlying factors often cause plant-breeding capacity building to be viewed as a second- or 
third-best option in funding decisions. In so doing, processes such as current reform of the CGIAR, restructuring of regional SROs and alignment with the CAADP process, and continuing vacillations in donor support to agriculture become important factors conditioning the ability to develop an efficient and integrated plant-breeding system for the continent.

\section{Notes}

* This article is a summary of a larger paper produced for the Global Initiative on Plantbreeding Capacity Building (GIPB) of the Food and Agricultural Organisation. The funding provided by GIPB is gratefully acknowledged. The interaction with Elon Gilbert and Howard Elliott in the design and writing of this study is gratefully acknowledged.

1 IRD was previously the Office de Recherche Scientifique et Technique d'Outre-Mer

\section{References}

Acosta-Gallegos, J.A.; Kelly, J.D. and Gepts, P. (2007) 'Prebreeding in Common Bean and Use of Genetic Diversity from Wild Germplasm', Crop Science 47: 44-59

Beintema, N.M. and Stads, G-J. (2006) Agricultural RED in Sub-Saharan Africa: An Era of Stagnation, ASTI, Washington DC: IFPRI

Byerlee, D. and Dubin, H. (2008) 'Crop Improvement in the CGIAR as a Global Success Story of Open Access and International Collaboration', keynote paper for the International Conference on the Microbial Commons, Ghent, Belgium, 12-13 June 2009

Byerlee, D. and Traxler, G. (2001) 'The Role of Technology Spillovers and Economies of Size in the Efficient Design of Agricultural Research Systems', in J.M. Alston, P.G. Pardey and M.J. Taylor (eds), Agricultural Science Policy: Changing Global Agendas, Baltimore: Johns Hopkins University Press

DeVries, J. and Toenniessen, G. (2001) Securing the Harvest: Biotechnology, Breeding and Seed Systems for African Crops, London: CABI and ODI

Eicher, C. (2001) 'Africa's Unfinished Business: Building Sustainable Agricultural Research Systems', Staff Papers 11802, East Lansing MI: Michigan State University

FARA (Forum for Agricultural Research in Africa) (2006) Framework for African Agricultural Productivity, Accra, Ghana: FARA
Many important organisational components are already in place, but there remains the absence of a compelling vision for how the particular domain of plant breeding can be effectively integrated, coordinated and managed to produce an increasing flow of improved varieties to African farmers.

(ORSTOM), the French Institute for Scientific Research for Development and Cooperation.

2 The three key sub-regional organisations (SROs) are ASARECA, CORAF/WECARD and SACCAR, mentioned above. The three key Regional Economic Communities (RECs) are the Common Market for Eastern and Southern Africa (COMESA), the Economic Community of West African States (ECOWAS) and the Southern African Development Community (SADC).

Kling, J. (2007) 'Varietal Development', in N. Minot, M. Smale, C. Eicher, T. Jayne, J. Kling, D. Horna and R. Myers (eds), Seed Development Programs in Sub-Saharan Africa: A Review of Experiences, Washington DC: IFPRI

Maredia, M.K. and Byerlee, D. (2000) 'Efficiency of Research Investments in the Presence of International Spillovers: Wheat Research in Developing Countries', Agricultural Economics 22.1: $1-16$

Maredia, M.K. and Raitzer, D.A. (2006) CGIAR and NARS Partner Research in Sub-Saharan Africa: Evidence of Impact to Date, Rome: Science Council Secretariat of the Consultative Group on International Agricultural Research

Minot, N.; Smale, M.; Eicher, G.K.; Jayne, T.; Kling, J.; Horna, D. and Myers, R. (eds) (2007) Seed Development Programs in Sub-Saharan Africa: A Review of Experiences, Washington DC: IFPRI

Oemke, J. (1992) The Impact of Agricultural Technology in Sub-Saharan Africa, Bureau for Africa, Office of Analysis, Research, and Technical Support, Technical Paper 3, Washington DC: USAID

Oruko, L. (2008) International Research Partnerships Support to Regional Collective Action in Eastern and Central Africa, Entebbe: ASARECA

Pardey, P. and Beintima, N. (2001) Slow Magic: Agricultural RED a Century after Mendel, Food Policy Reports 13, Washington DG: IFPRI

Pardey, P.; James, J.; Alston, J.; Wood, S.; Koo, B.; Binenbaum, E.; Hurley, T. and Glewwe, P. 
(2007) Science, Technology and Skills, Minneapolis, MN: INSTEPP, University of Minnesota

Purcell, D.L. and Anderson, J.R. (1997)

Agricultural Extension and Research: Achievements and Problems in National Systems, A World Bank

Operations Evaluation Study, Washington DG: World Bank

Smale, M. and Heisey, P. (1994) 'Maize Research in Malawi Revisited: An Emerging Success

Story?', Journal of International Development 6.6: 689-706

Sumberg, J. (2005) 'Systems of Innovation Theory and the Changing Architecture of Agricultural Research in Africa', Food Policy 30: 21-41
Sumberg, J. and Blackie, M. (2004) 'Income Diversity, Technology Choice and Agricultural Research Policy in Sub-Saharan Africa', Development Policy Review 2.2: 131-46

Traxler, G. and Pingali, P.L. (1999) International Collaboration in Crop Improvement Research: Current Status and Future Prospects, CIMMYT Economics Working Paper 11, Mexico DF: CIMMYT

World Bank (2008) Project Appraisal Document for Agricultural Development Program Support Project, Washington DC: World Bank

World Bank (2006) Agriculture Investment

Sourcebook, Washington DC: World Bank 